\title{
The INGV tectonomagnetic network in Central Italy. Fifteen years of observa- tions and future developments: an update
}

\author{
Domenico Di Mauro $\left({ }^{1}\right)$, Manuele Di Persio $\left({ }^{2}\right)$ Stefania Lepidi $\left({ }^{2}\right)$, Fabrizio Masci $\left({ }^{2}\right)$, \\ Giuliana Mele $\left({ }^{1}\right)$, Antonio Meloni $\left({ }^{1}\right)$ and Paolo Palangio $\left({ }^{2}\right)$ \\ (1) Istituto Nazionale di Geofisica e Vulcanologia, Roma, Italy \\ ${ }^{(2)}$ Istituto Nazionale di Geofisica e Vulcanologia, L'Aquila, Italy
}

\begin{abstract}
Tectonic events, like earthquakes and volcanic eruptions, may generate variations in the local geomagnetic field intensity. To detect possible effects related to seismic activity in central Italy, the INGV (Istituto Nazionale di Geofisica e Vulcanologia) installed a network of four magnetometers in 1989 , in a region extending from $41^{\circ}$ to $43^{\circ}$ latitude $\mathrm{N}$ and $12^{\circ}$ to $15^{\circ}$ longitude $\mathrm{E}$. The study area is characterized by active faulting and seismicity, and by historical destructive earthquakes. The total geomagnetic field intensity was synchronously sampled at the magnetometer sites since July 1989 and averaged on a daily basis. These values were then differentiated with respect to the data recorded at the permanent nearby National Geomagnetic Observatory of L'Aquila $\left(42^{\circ} 23^{\prime} \mathrm{N}\right.$, $13^{\circ} 19^{\prime} \mathrm{E}$ ). The aim of our work was to detect possible significant magnetic field variations of tectonic origin. Data have been regularly recorded for about 15 years with some interruptions due to instrumental temporary failures. This data set represents a long series of recordings that is valuable to characterize the local response of each station to the secular variation in a tectonically active area. In this paper we applied a new signal processing on data by means of a wavelet analysis to the differentiated geomagnetic records for the period 2000-2005. In an ongoing paper the same technique is extended back to the remaining ten years of data (1989-1999).
\end{abstract}

Key words seismomagnetism - geomagnetic field earthquakes

\section{Introduction}

«Tectonomagnetism» is a general term used to classify the experimental investigations of magnetic, electric and electromagnetic (EM) effects caused by tectonic events. Physical processes related to earthquake and volcanic activity can generate anomalous signals, in

Mailing address: Dr. Domenico Di Mauro, Istituto Nazionale di Geofisica e Vulcanologia, Via di Vigna Murata 605, 00143 Roma, Italy; e-mail: dimauro@ingv.it these cases the terms «seismomagnetism» and «volcanomagnetism» are preferred. In recent decades, observations carried out in many areas of the world using specific networks have lead to the identification of signals clearly related to tectonic events.

The complexity of the tectonomagnetic phenomena arises from two main causes: the signal variations have been reported to occur in a wide range of frequency (from DC to VHF), and the effects could be strongly dependent on the phenomenon intensity and the distance between signal source and monitoring equipment. For these reasons, up to now, an ultimate explanation of the physical mechanisms behind the observed phenomena is still not defined.

At low frequency the most supported explanations for the observed variation of the local geomagnetic field, generally not greater than 
few nT, are related to piezomagnetic and/or electrokinetic effects into the rock volumes where thermomechanical and electrolytic processes could occur during the preparation phase of tectonic events. Moreover, EM field emissions (ULF/ELF/VLF bands) generally lead to charge redistribution into the rocks or piezoelectric effects.

In the frame of the seismomagnetic approach, the accuracy of local magnetic field measurements depends on the sampling frequency, the spatial scale, instrument type, and the choice of site location. Measurement systems can be contaminated by anthropic noise, ionosphere and magnetosphere electrical cur- rents. It is generally accepted by the geophysical community that within low-frequency range observations (up to Hertz) of magnetic field variations, the use of a reference station, equipped with a scalar magnetometer to isolate and eliminate external noise, is common (Johnston, 1997 and reference therein).

At higher frequencies observations made by vectorial magnetometers, placed in a network configuration with appropriate site spacing, would be essential to better understand the generating mechanism, discerning the space where the signals are really generated. Networks of synchronous absolute total field magnetometers have been set up in many seismogenic and vol-
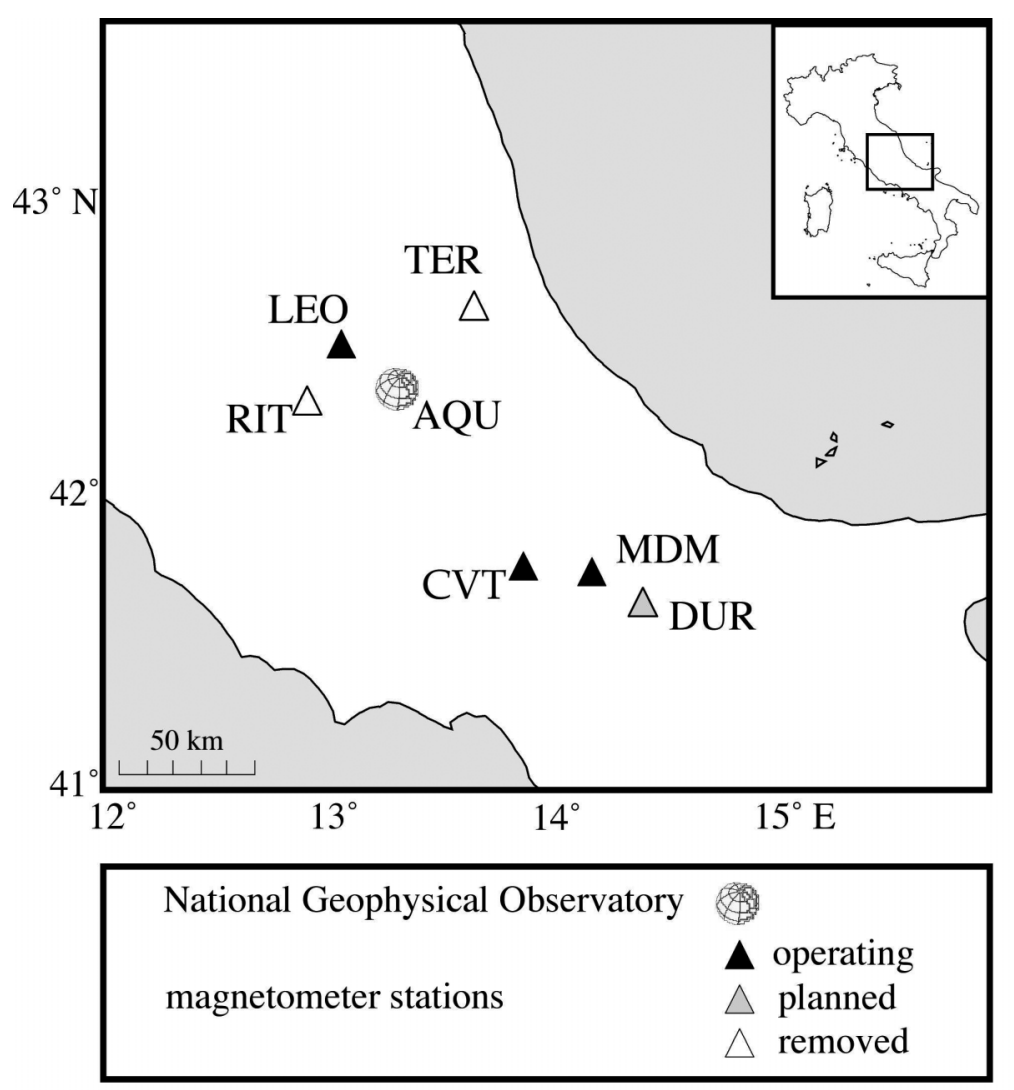

Fig. 1. Map of the study area showing the location of the magnetometer sites described in the text and the National Geomagnetic Observatory of L'Aquila. 
canic areas of the world to detect anomalous magnetic field changes related to seismic and volcanic activity. Magnetic field changes of tectonic origin are easily detected by comparing data from adjacent sites. The use of total field absolute magnetometers ensures that measurements are indeed unaffected by mislevelling or thermal drifts typical of vectorial magnetometers. Approaches with the use of vectorial magnetometers are at times applied in volcanic or in known active fault areas where higher frequency observations could be aimed to quasi realtime monitoring. However the levelling of the three component magnetometers must be continuously monitored. For long-term observations and for unclear distribution of faults, it is crucial to maintain unchanged the position of the recording stations, which is often the hard result of a compromise between the choice of remote, still accessible locations and their distance from anthropic disturbances (like the Italian railway network), giving statistical meaning to any obtained result.

For an extensive and updated documentation on these topics refer to papers by Johnston and Parrott (1998), Hayakawa and Molchanov (2002), Johnston (2002) and references therein.

\section{The magnetometers network}

In the tectonically active region of central Italy, between $41^{\circ}$ and $43^{\circ}$ latitude $\mathrm{N}$ and $12^{\circ}$ and $15^{\circ}$ longitude $\mathrm{E}$, the total magnetic field intensity $\mathrm{F}$ have been simultaneously recorded since July 1989 at several sites: Monte di Mezzo (MDM), Civitella Alfedena (CVT), Leonessa (LEO), Rieti (RIT), Teramo (TER) and the L'Aquila National Geomagnetic Observatory (AQU). Two more stations are planned to be installed in 2007, one located in Duronia (DUR) and another in a site, not yet selected, between AQU and CVT (see fig. 1 for stations location).

At each station, a proton precession magnetometer with $0.1 \mathrm{nT}$ accuracy operates at a sampling rate of $15 \mathrm{~min}$. During the fifteen years of operation, two stations were definitively removed for technical and logistic difficulties: TER, which provided data up to the first months of 1990, and RIT closed in August
2002. Station LEO was briefly operating between 1990 and 1991 and restored since 2003.

Daily averages of the total field scalar $\mathrm{F}$ of AQU, RIT, CVT, MDM and LEO are calculated to remove the daily variations (fig. 2). Steady positive secular variations of about 28$30 \mathrm{nT} / \mathrm{yr}$ are observed for each station. As is known, the magnetic planetary activity is modulated by the solar cycle which had a minimum during the period 1993-1999. In that time interval the high-frequency variations decrease significantly in each curve of fig. 2.

Two contributions not related to possible tectonomagnetic effects must be removed from each station: a) effects from external electric currents flowing in the ionosphere and magnetosphere and b) contributions from the Earth's interior, i.e., the secular variation. They can be removed by computing simple differences between the absolute geomagnetic field intensity $F$ measured at each station and at the reference L'Aquila Observatory. The remaining part of the signal can be related to local variations in the crustal magnetization and tectonic activity.

Simple differences of the daily averaged data are computed between CVT, MDM and AQU for the years 2000-2005 (fig. 3). For the previous years which include the signal from RIT station, no longer running, refer to Meloni et al. (2004) and Di Mauro et al. (2005). The sudden and persistent changes in the signal level reported in the cited papers were ignored in the current analysis because they were interpreted as artificial since no satisfactory explanation for a possible physical origin was found. Further tests are in progress to establish the nature of such changes (see Masci et al., 2006).

\section{Tectonic setting and seismicity of Central Italy}

Italy is one of the most seismically active areas in the Mediterranean region. In peninsular Italy, where the study area is located, seismic activity mainly occurs along the NW-SE-trending Apennine mountain belt. This chain, formed since the early Miocene, attains the highest elevation in Central Italy with several mountains exceeding $2000 \mathrm{~m}$. The Central 


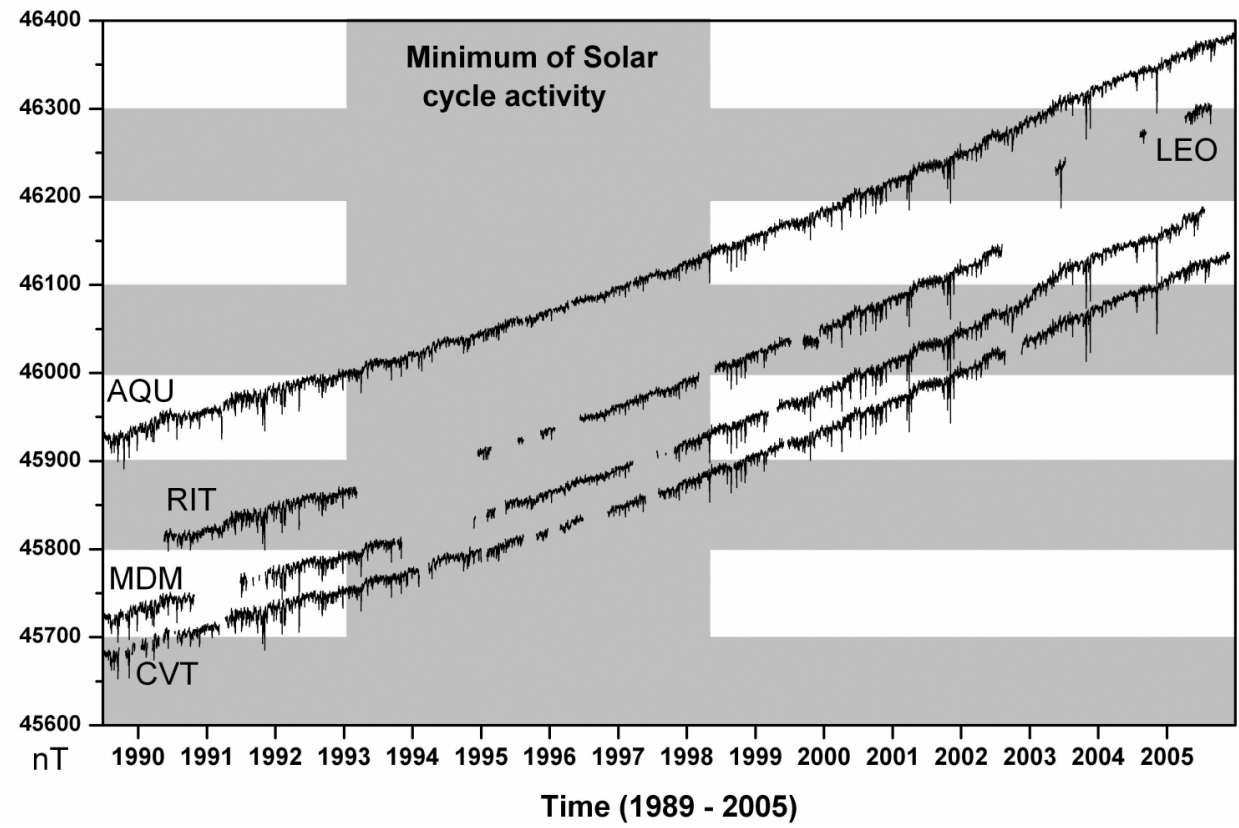

Fig. 2. Scalar $\mathrm{F}$ at each station of the network for the time interval July 1989-2005. Station LEO starts operating in 2003.

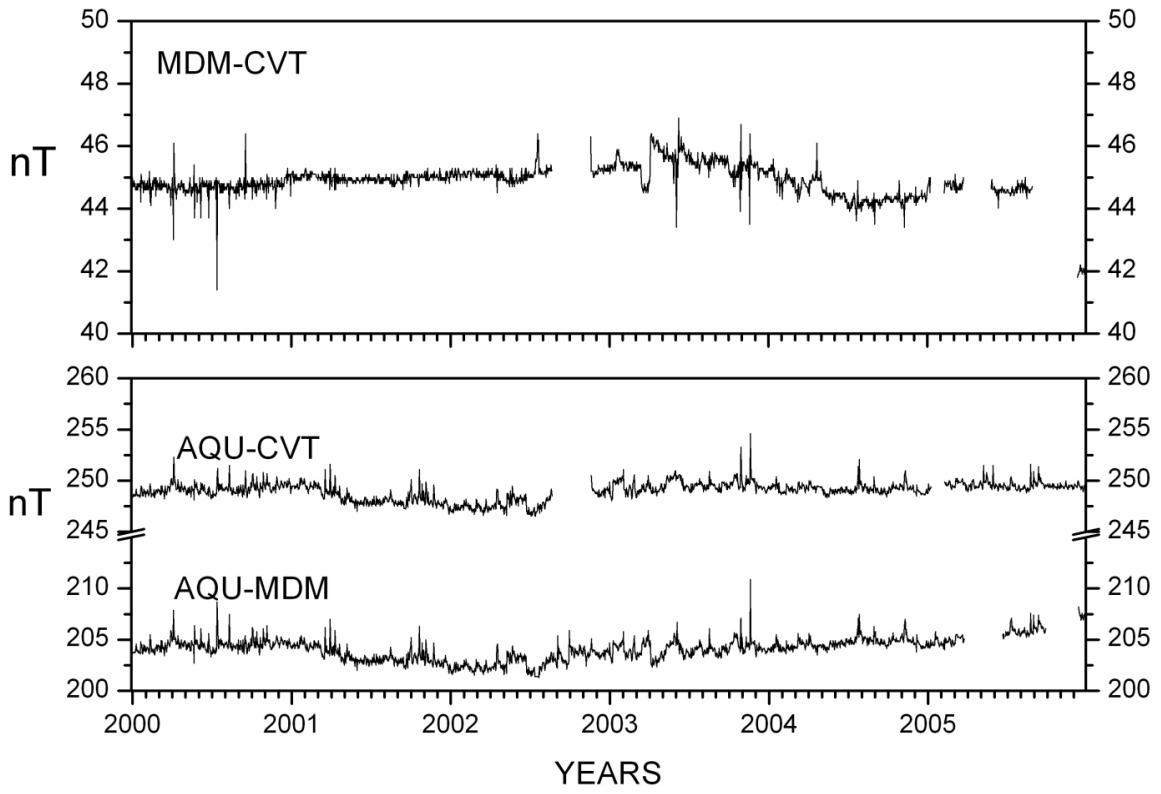

Fig. 3. Differences of the daily averages between MDM and CVT signals (top frame) and between AQU, MDM and CVT signals (bottom frame) for the years 2000-2005. 
Apennines are characterized by thick MesoCenozoic basinal and platform carbonate sequences. The main thrusts strike NW-SE and are embricated eastward onto Neogene clayey and arenaceous flysch units, while normal faults and extensional basins of post-Messinian age are superimposed onto the thrust units (fig. 4). The western Tyrrhenian margin of central Italy is characterized by large Quaternary volcanic deposits.

Central Italy was affected in past centuries by several destructive earthquakes (table I) shown in fig. 5 along with the $M \geq 4.0$ events recorded from July 1989 to 2005 (table II) by the National Seismic Network operated by the INGV. The recent seismicity does not exceed $M=5.8$ and hypocenters are mainly shallow and clustered along the ridge of the Apennine chain and in the Adriatic Sea. In late 2002 a short seismic sequence with maximum magnitude 5.4 occurred about $50 \mathrm{~km}$ east of the MDM station (fig. 5).

Figure 6 shows the time evolution of the seismic activity in the study period. Earthquakes (arrows) are plotted versus their magnitude and distance between the epicentre and each seismomagnetic site which gives an indication of the level of seismic energy felt by each station. The
Table I. Major historical earthquakes occurred in the study area. Me indicates the estimated magnitude. Earthquake parameters are from the Parametric Catalogue of Italian Earthquakes (CPTI, 1999).

\begin{tabular}{ccccc}
\hline \hline$\#$ & Date & Me & Lat $(\mathrm{N})$ & Lon $(\mathrm{E})$ \\
\hline 1 & $11 / 10 / 1125$ & 7.0 & 41.60 & 15.00 \\
2 & $04 / 09 / 1293$ & 6.8 & 41.30 & 14.55 \\
3 & $05 / 09 / 1349$ & 6.7 & 41.48 & 14.07 \\
4 & $09 / 09 / 1349$ & 7.1 & 42.17 & 13.38 \\
5 & $05 / 12 / 1456$ & 7.1 & 41.30 & 14.71 \\
6 & $14 / 01 / 1703$ & 6.8 & 42.68 & 13.12 \\
7 & $02 / 02 / 1703$ & 6.7 & 42.47 & 13.20 \\
8 & $03 / 11 / 1706$ & 6.7 & 42.08 & 14.08 \\
9 & $13 / 01 / 1915$ & 7.0 & 42.01 & 13.53
\end{tabular}

strongest effect on the magnetic signal is expected at the site closest to the epicentre.

\section{Data analysis and discussion}

Magnetic data were collected in fifteen years by the INGV seismomagnetic network to detect
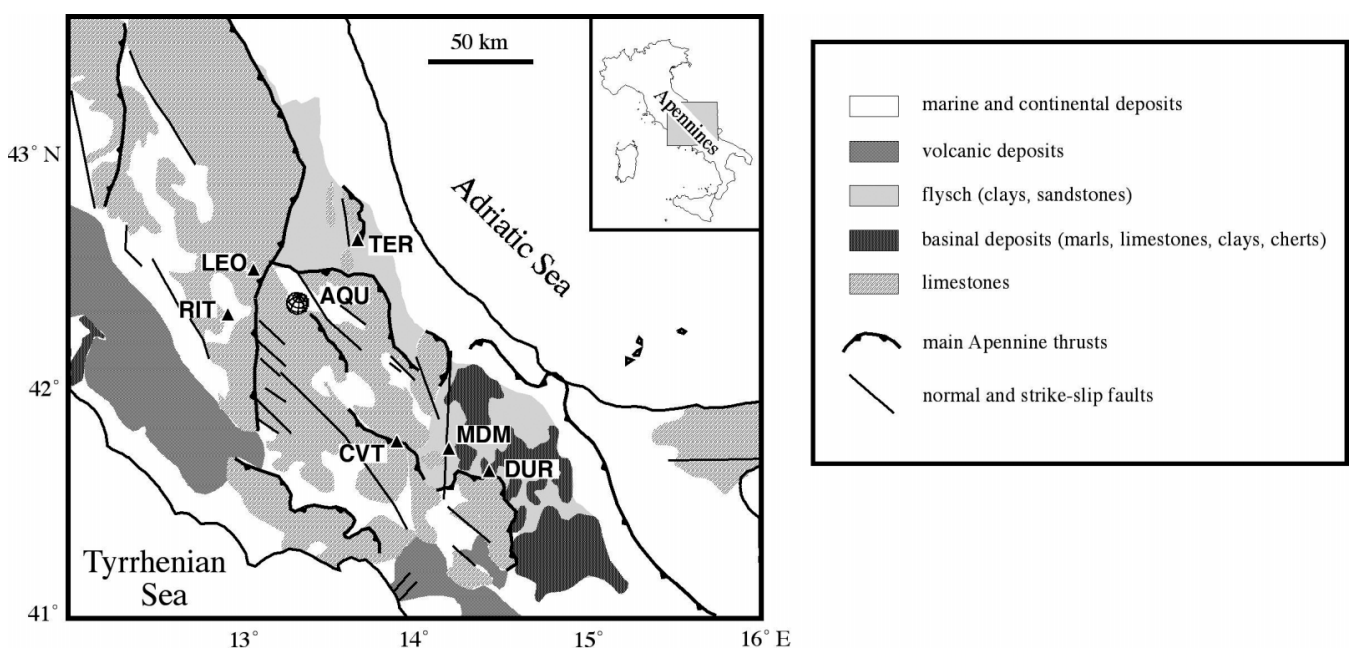

Fig. 4. Map of central Italy showing the main geologic and tectonic features. 


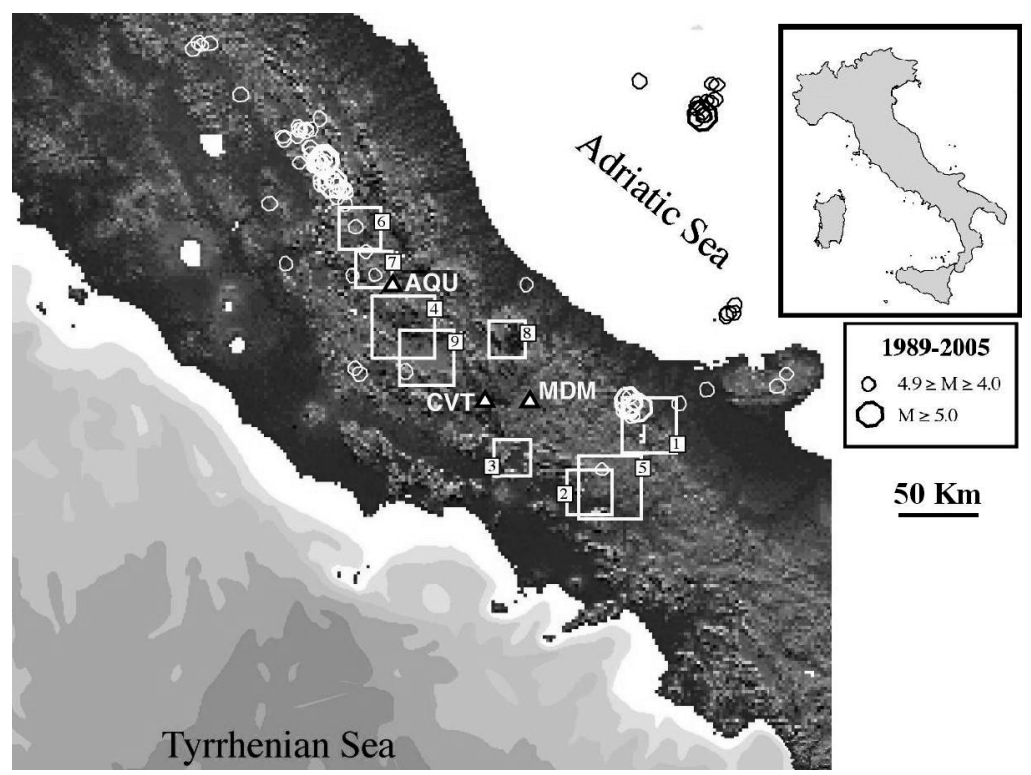

Fig. 5. Topography map showing the location of the seismomagnetic stations used in this study (triangles), the largest historical events (squares; numbers refer to table I) and the epicentres of earthquakes with magnitude $\geq 4.0$ (circles; see table II) occurred in the study period within $41^{\circ}-44^{\circ}$ latitude $\mathrm{N}$ and $12^{\circ}-16^{\circ}$ longitude $\mathrm{E}$.

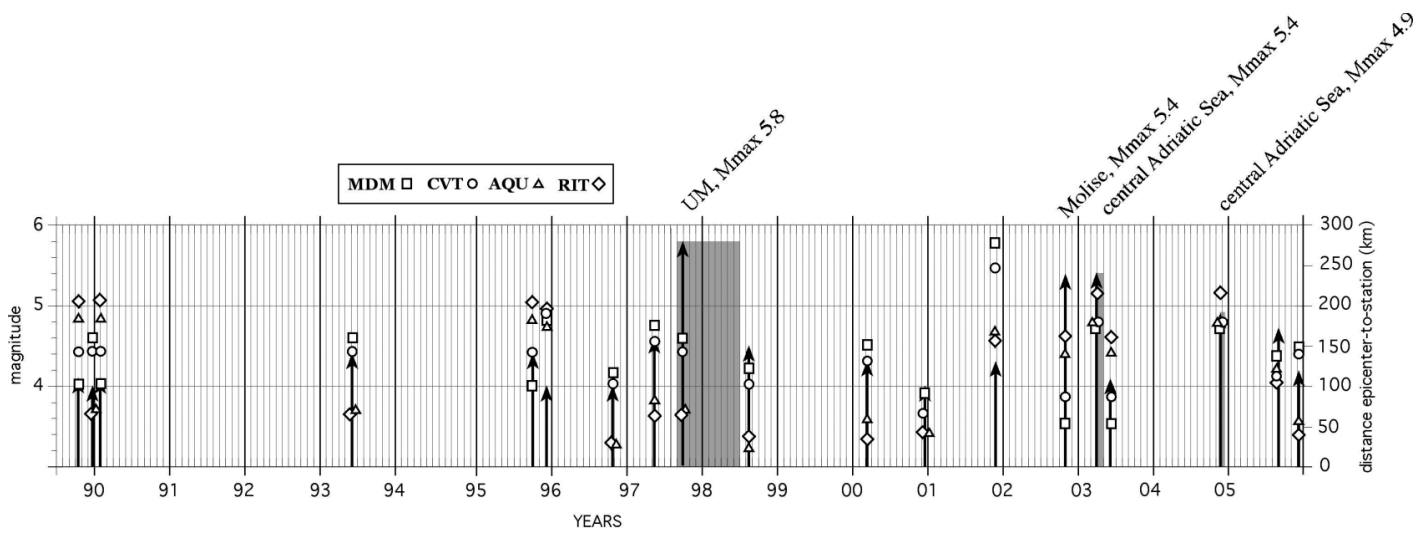

Fig. 6. Time-space distribution of seismic activity referred to the seismomagnetic sites. Arrows indicate earthquakes occurrence and magnitude (see table II). Grey bands represent the duration of seismic sequences for which only the event with the largest magnitude has been indicated. For each earthquake is also indicated the distance from the station sites using different symbols. 
Table II. Earthquakes with $M_{l} \geq 4.0$ selected within latitude $41^{\circ}-44^{\circ} \mathrm{N}$ and longitude $12^{\circ}-15^{\circ} \mathrm{E}$ from July 1989 to 2005. Earthquake parameters are from the INGV Seismic Bulletin (INGV, 2006).

\begin{tabular}{|c|c|c|c|c|c|c|c|c|}
\hline \# & Year & Month & Day & Origin time & Lat. N & Lon. E & Depth & Ml \\
\hline 1 & 89 & Oct & 6 & $17: 38$ & 42.166 & 15.591 & 5.0 & 4.1 \\
\hline 2 & 89 & Dec & 22 & $06: 48$ & 43.016 & 12.761 & 22.4 & 4.0 \\
\hline 3 & 90 & Feb & 1 & $06: 24$ & 42.131 & 15.584 & 5.0 & 4.1 \\
\hline 4 & 93 & Jun & 5 & $19: 16$ & 43.152 & 12.666 & 5.0 & 4.4 \\
\hline 5 & 95 & Sep & 30 & $10: 14$ & 41.802 & 15.904 & 21.8 & 4.4 \\
\hline 6 & 95 & Dec & 5 & 01:01 & 43.299 & 15.057 & 10.0 & 4.0 \\
\hline 7 & 96 & Oct & 20 & 19:06 & 42.559 & 13.163 & 5.0 & 4.0 \\
\hline 8 & 97 & May & 12 & $13: 50$ & 42.829 & 12.542 & 5.0 & 4.6 \\
\hline 9 & 97 & Sep & 3 & $22: 07$ & 43.059 & 12.842 & 5.0 & 4.4 \\
\hline 10 & 97 & Sep & 26 & $00: 33$ & 43.018 & 12.913 & 7.9 & 5.6 \\
\hline 11 & 97 & Sep & 26 & 09:40 & 43.024 & 12.926 & 5.5 & 5.8 \\
\hline 12 & 97 & Sep & 27 & 08:08 & 43.090 & 12.842 & 7.3 & 4.3 \\
\hline 13 & 97 & Sep & 27 & $17: 13$ & 43.019 & 12.901 & 4.6 & 4.0 \\
\hline 14 & 97 & Sep & 27 & $19: 56$ & 43.035 & 12.936 & 5.0 & 4.0 \\
\hline 15 & 97 & Oct & 2 & $10: 59$ & 43.087 & 12.835 & 9.6 & 4.0 \\
\hline 16 & 97 & Oct & 2 & $19: 38$ & 43.616 & 12.163 & 5.0 & 4.1 \\
\hline 17 & 97 & Oct & 2 & $21: 38$ & 43.629 & 12.150 & 4.5 & 4.0 \\
\hline 18 & 97 & Oct & 3 & 08:55 & 43.023 & 12.890 & 4.7 & 4.7 \\
\hline 19 & 97 & Oct & 4 & $06: 49$ & 42.914 & 12.935 & 5.0 & 4.1 \\
\hline 20 & 97 & Oct & 4 & $15: 07$ & 42.920 & 12.983 & 4.2 & 4.1 \\
\hline 21 & 97 & Oct & 4 & $16: 13$ & 42.917 & 12.977 & 4.0 & 4.3 \\
\hline 22 & 97 & Oct & 4 & $18: 47$ & 42.917 & 12.973 & 5.0 & 4.3 \\
\hline 23 & 97 & Oct & 6 & $23: 24$ & 43.010 & 12.918 & 3.4 & 5.4 \\
\hline 24 & 97 & Oct & 7 & 05:09 & 43.010 & 12.919 & 5.2 & 4.1 \\
\hline 25 & 97 & Oct & 12 & 11:08 & 42.897 & 13.008 & 5.0 & 4.7 \\
\hline 26 & 97 & Oct & 13 & 11:01 & 42.878 & 13.051 & 3.5 & 4.0 \\
\hline 27 & 97 & Oct & 13 & 13:09 & 42.864 & 13.002 & 3.7 & 4.0 \\
\hline 28 & 97 & Oct & 14 & $15: 23$ & 42.907 & 12.969 & 4.6 & 5.5 \\
\hline 29 & 97 & Oct & 15 & $22: 53$ & 42.922 & 12.992 & 5.7 & 4.1 \\
\hline 30 & 97 & Oct & 16 & $12: 00$ & 43.032 & 12.898 & 7.9 & 4.1 \\
\hline 31 & 97 & Oct & 25 & 03:08 & 42.800 & 13.049 & 4.9 & 4.0 \\
\hline 32 & 97 & Nov & 8 & $15: 31$ & 42.862 & 13.052 & 10.0 & 4.0 \\
\hline 33 & 97 & Nov & 9 & $19: 07$ & 42.854 & 13.059 & 10.7 & 4.6 \\
\hline 34 & 97 & Dec & 31 & $16: 02$ & 42.834 & 13.000 & 5.0 & 4.0 \\
\hline 35 & 98 & Mar & 21 & $16: 45$ & 42.979 & 12.905 & 5.0 & 4.1 \\
\hline 36 & 98 & Mar & 26 & $16: 26$ & 43.175 & 12.860 & 47.8 & 4.7 \\
\hline 37 & 98 & Apr & 3 & $07: 26$ & 43.177 & 12.786 & 9.6 & 4.7 \\
\hline 38 & 98 & Apr & 3 & 07:59 & 43.189 & 12.774 & 9.2 & 4.0 \\
\hline 39 & 98 & Apr & 5 & $15: 52$ & 43.177 & 12.775 & 10.0 & 4.5 \\
\hline 40 & 98 & Jun & 2 & $23: 11$ & 43.169 & 12.817 & 9.5 & 4.2 \\
\hline
\end{tabular}


Table II (continued).

\begin{tabular}{lcccccccc}
\hline \hline$\#$ & Year & Month & Day & Origin time & Lat. N & Lon. E & Depth & Ml \\
\hline 41 & 98 & Jun & 5 & $21: 53$ & 43.179 & 12.818 & 9.4 & 4.1 \\
42 & 98 & Aug & 15 & $05: 18$ & 42.446 & 13.059 & 5.0 & 4.5 \\
43 & 00 & Mar & 11 & $10: 35$ & 41.956 & 13.068 & 5.0 & 4.3 \\
44 & 00 & Dec & 16 & $07: 31$ & 42.528 & 12.625 & 7.7 & 4.0 \\
45 & 01 & Nov & 26 & $00: 56$ & 43.601 & 12.108 & 5.0 & 4.3 \\
46 & 02 & Oct & 31 & $10: 32$ & 41.682 & 14.897 & 10.0 & 5.4 \\
47 & 02 & Nov & 1 & $15: 09$ & 41.719 & 14.840 & 10.0 & 5.3 \\
48 & 02 & Nov & 1 & $15: 19$ & 41.742 & 14.848 & 10.0 & 4.1 \\
49 & 02 & Nov & 1 & $17: 21$ & 41.714 & 14.879 & 10.0 & 4.2 \\
50 & 02 & Nov & 4 & $00: 35$ & 41.703 & 14.869 & 10.0 & 4.2 \\
51 & 02 & Nov & 12 & $09: 27$ & 41.677 & 14.799 & 10.0 & 4.2 \\
52 & 03 & Mar & 27 & $16: 10$ & 43.095 & 15.419 & 10.0 & 4.7 \\
53 & 03 & Mar & 29 & $17: 42$ & 43.109 & 15.464 & 10.0 & 5.4 \\
54 & 03 & Mar & 30 & $00: 56$ & 43.170 & 15.435 & 10.0 & 4.3 \\
55 & 03 & Mar & 30 & $11: 09$ & 43.169 & 15.527 & 10.0 & 4.6 \\
56 & 03 & Apr & 26 & $08: 20$ & 43.182 & 15.549 & 10.0 & 4.0 \\
57 & 03 & Apr & 27 & $19: 12$ & 43.260 & 15.539 & 10.0 & 4.1 \\
58 & 03 & Apr & 29 & $15: 13$ & 43.254 & 15.572 & 10.0 & 4.4 \\
59 & 03 & Jun & 1 & $15: 45$ & 41.661 & 14.821 & 11.8 & 4.1 \\
60 & 04 & Nov & 25 & $06: 21$ & 43.132 & 15.443 & 10.0 & 4.9 \\
61 & 04 & Dec & 3 & $08: 13$ & 43.087 & 15.504 & 10.0 & 4.2 \\
62 & 04 & Dec & 17 & $01: 42$ & 43.092 & 15.371 & 10.0 & 4.2 \\
63 & 05 & Aug & 22 & $12: 02$ & 41.435 & 12.501 & 30.0 & 4.7 \\
64 & 05 & Dec & 15 & $13: 28$ & 42.738 & 12.760 & 18.4 & 4.2 \\
\hline
\end{tabular}

possible effects related to seismic activity in Central Italy. The study area is characterized by active faulting and seismicity, and by historical destructive earthquakes. In this paper the total geomagnetic field intensity, synchronously sampled at several magnetometer sites, have been averaged on a daily basis and differentiated, in the time window 2000-2005 (see fig. 3), with respect to the data recorded at the nearby permanent Geomagnetic Observatory of L'Aquila. This analysis shows no clear evidence of anomalies of crustal origin related to seismic activity.

In the upper panel of fig. 7, the simple differences AQU-CVT and AQU-MDM are plotted along with the magnetic activity index $\mathrm{Kp}$, which allows us to relate most of the spikes to intense magnetic field sources of external ori- gin, corresponding to high values and variability of the $K p$ index. A wavelet analysis was then applied to the same differences. We used the Morlet «mother wavelet» (Torrence and Compo, 1998) to compute the dynamic power spectra shown in the bottom panels of fig. 7. Apart from the high power content in the signal related to high values of $K p$, a remarkable power enhancement with period around 4 days can be observed at the end of May 2003 (May 29-June 2 ) in the difference AQU-MDM and, less pronounced, in the difference AQU-CVT. On June 1 st an earthquake of magnitude 4.1 occurred $\sim 50 \mathrm{~km}$ east of MDM station (event \# 59 in table II). It is important to note that this period was characterized by a low $K p$ index and perturbations of magnetospheric origin are absent. 


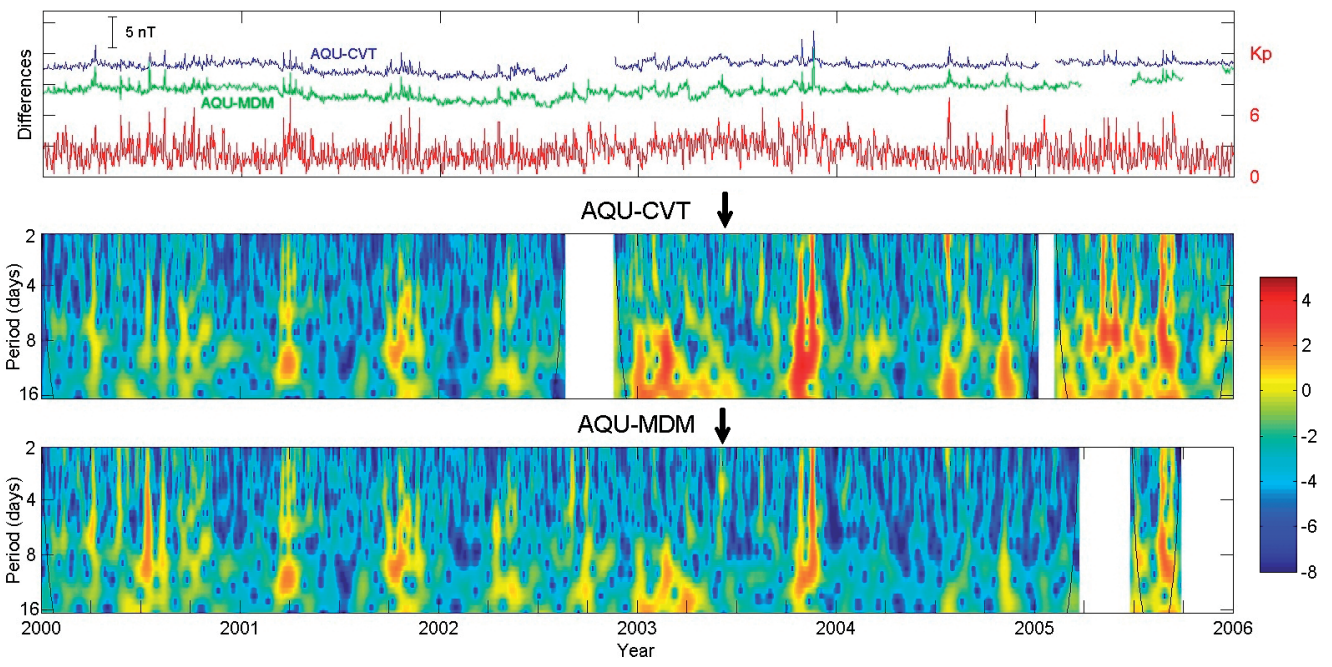

Fig. 7. Upper panel: difference curves and Kp index for the years 2000-2005. Lower panels: dynamic spectrum in log scale of the differences AQU-CVT and AQU-MDM for the years 2000-2005. White bands correspond to missing data. Colored bar indicates the power density in $\mathrm{nT} 2 / \mathrm{Hz}$. Black arrows indicate the power enhancement occurred at the end of May 2003.

However, two events of magnitude 5.4 and 5.3 (events \# 45 and 46 in table II), wich occurred at the end of November 2002 in the same epicentral area, did not generate a similar effect.

We consider the wavelet analysis as promising in this kind of investigations. Further steps will be the application of this technique to the whole dataset with a multi-station approach to provide an advanced signal-processing technique to classify the source of the geomagnetic variations which could be considered as «precursors» against a number of unrelated variations as suggested in the paper of Fedi et al. (2003). At the same time a better characterization of the earthquakes mechanism in search of possible relationships between magnetic and seismic signals in this area would be advisable to refine the methodology itself.

\section{Acknowledgements}

The authors thank the INGV L'Aquila Geomagnetic Observatory staff for the technical support to the research activities.

\section{REFERENCES}

CPTI Working Group (1999): Catalogo Parametrico dei Terremoti Italiani (ING, GNDT, SGA, SSN, Bologna), pp. 92

Di Mauro, S. Lepidi, A. Meloni and P. Palangio (2005): Magnetic and Electromagnetic signals related to tectonic activity: updates and new analyses on measurements in Central Italy, Nat. Hazards Earth Syst. Sci., 5, 925-930.

Fedi, M., M. LA MAnNa and F. PALmieri (2003): Nonstationary analysis of geomagnetic time sequences from Mt. Etna and North Palm Springs earthquake, J. Geophys. Res., 108 (B10), 2493, doi: 10.1029/2001JB000820

HaYaKaWA, M. and O.A. Molchanov (Editors) (2002): Seismo Electromagnetics: Lithosphere-AtmosphereIonosphere Coupling (TERRAPUB, Tokyo), pp. 477.

INGV (2006): Seismic Bullettin, (Istituto Nazionale di Geofisica e Vulcanologia, Roma).

Johnston, M.J.S. (1997): Review of electric and magnetic fields accompanying seismic and volcanic activity, Surv. Geophys., 18, 441-475.

Johnston, M.J.S. (2002): Electromagnetic fields generated by earthquakes, in International Handbook of Earthquake and Engineering Seismology, edited by W. LEE, H. Kanamori, P. Jennings and K. Kisslinger (Academic Press), 621-634.

Johnston, M.J.S. and M. PARRot (1998): Electromagnetic effects of earthquakes and volcanoes, Phys. Earth Planet. Int. (Spec. Vol.), 105, 109-295.

Masci, F., P. Palangio and A. Meloni (2006): The INGV 
tectonomagnetic network: 2004-2005 preliminary dataset analysis, Nat. Hazards Earth Syst. Sci., 6, 773-777.

Meloni, A., D. Di Mauro, S. Lepidi, G. Mele and P. PALANGIO (2004): Tectonomagnetic and VLF electro- magnetic signals in Central Italy, Ann. Geophys., 47 (1), 29-34.

Torrence, C. and G.P. Compo (1998): A practical guide to wavelet analysis, Bull. Am. Meteorol. Soc., 79, 61-78. 